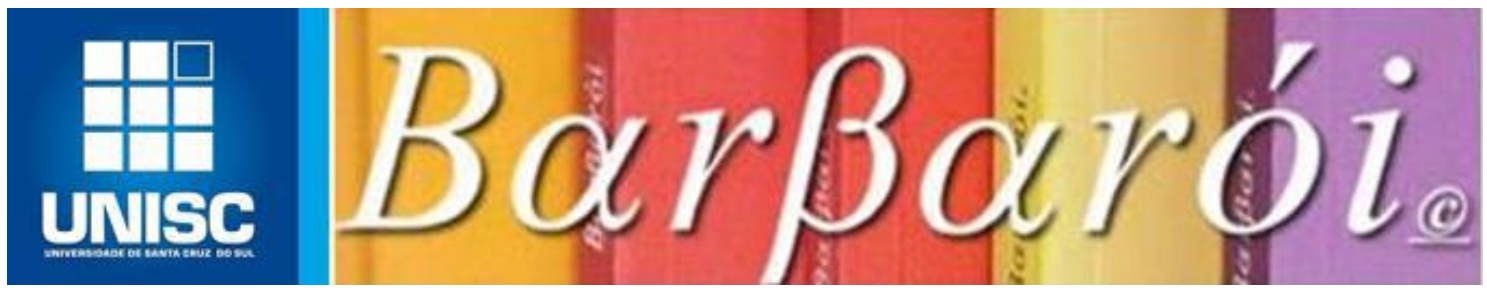

\title{
TRAJETÓRIAS DE SUCESSO ESCOLAR ENTRE ESTUDANTES DA ESCOLA PÚBLICA NA UNIVERSIDADE: UM PROBLEMA SENSÍVEL?
}

\author{
DOI: http://dx.doi.org/10.17058/barbaroi.v0i0.14595
}

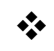 \\ Jorge Morgan de Aguiar Neto \\ Pontifícia Universidade Católica do Rio Grande do Sul - PUCRS - Brasil

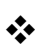

\begin{abstract}
Resumo
Este artigo faz um apanhado das principais contribuições de pesquisas nacionais que descrevem e problematizam trajetórias escolares e/ou universitárias de sucesso de jovens oriundos de meios populares no Brasil, no período compreendido entre os anos 1990 e 2018. Tratado comumente no âmbito da Sociologia da Educação, esse tema é revisitado aqui a partir de diferentes abordagens e perspectivas, que se complementam, formando um painel da situação, que culmina com a mais recente expansão do sistema de ensino superior através da implementação de políticas públicas e programas assistenciais (vivida entre 2000 e 2016). A esse último período, é dedicado um estudo que abarca especificamente a transição de jovens do ensino médio público para formações universitárias consideradas de prestígio, em que se consideram suas características, mas também suas percepções do sucesso escolar. Além disso, em razão das especificidades da população analisada, das particularidades da própria pesquisa de campo empreendida, bem como pelo fato de esse tema afetar diretamente a igualdade de chances e, por conseguinte, a mobilidade social brasileira, propomos que este seja tratado como um tema sensível pelas Ciências Humanas e Sociais, abordagem discutida ao final do texto.
\end{abstract}

Palavras-chave: Sucesso escolar; estudantes de origem popular; Terrenos sensíveis.

\section{Introdução}

A observação das trajetórias dos estudantes oriundos da escola pública brasileira que entram em cursos universitários concorridos expõe as contradições socioeconômicas e culturais que marcam a estrutura social e a mobilidade de classes no país. Em um contexto de ensino marcado pela cisão, aprofundada historicamente, entre a escola pública e privada - que representa, de algum modo, as diferenças entre as classes sociais -, as trajetórias desses estudantes de meios populares podem ser consideradas de sucesso escolar, uma vez que superam as limitações em relação ao fraco capital econômico e/ou cultural de suas famílias e territórios de origem, tornando-se muitas vezes casos de exceção ou, como diz Lahire (1997), Barbarói, Santa Cruz do Sul, Edição Especial n.54, p.<94-111>, jul./dez. 2019 
casos improváveis de sucesso escolar. Cabe indagar-se então, primeiro, o que os torna diferentes dos demais estudantes da escola pública e, segundo, como, de fato, vivenciam o ambiente universitário, tradicionalmente seletivo e disputado.

Os estudantes de origem popular de média e baixa renda que superaram as barreiras seletivas e os gargalos do ensino médio público, e que se encontram hoje integrados ao sistema de ensino superior, constituem, dessa forma, um fenômeno relevante para um país que busca desenvolver-se. Esses jovens carregam em si a chave tanto para um universo que parece não ser destinado a eles, podendo vir a garantir meios de mobilidade e de ascensão social, inclusive para sua comunidade de origem, quanto para as políticas de educação, que lhes garantem igualdade de chances. Nesse sentido, o período compreendido entre os anos 2000 e 2016, representado pela mais recente expansão do sistema educacional brasileiro - com aumento das matrículas e da estrutura do ensino superior público e privado ${ }^{1}$, através da implementação de importantes políticas públicas e programas assistenciais, tais como Fies, Prouni, Pronatec, SISU, Reuni, Cotas Raciais, Pnaes, entre outras ações - é apontado como responsável pelos avanços em relação a esse tema. Portanto, a própria expansão educacional e seus efeitos só podem ser bem compreendidos se vistos em perspectiva com períodos anteriores a ela, e que já vinham sendo acompanhados pelos pesquisadores brasileiros. Alguns desses estudos serão aqui retomados com base em sua cronologia, formando uma rede de informações que nos permite rever o lugar que ocupam, nas Ciências Humanas e Sociais, as questões relativas à trajetória do estudante de origem popular no ensino superior.

\section{0 debate acerca do sucesso escolar na pesquisa brasileira}

A tentativa de conhecer essas trajetórias escolares, as características desses estudantes de sucesso escolar e suas motivações, tem levado os pesquisadores de campo a um grupo sociocultural (étnico) cada vez mais diversificado, mas reduzido se comparado à maioria dos estudantes matriculados nos cursos prestigiados. Os estudantes com sucesso escolar no contexto universitário são assim aqueles que, vindos da escola pública, conseguem superar os obstáculos da falta de capital social e cultural de seus grupos familiares e chegar aos patamares mais elevados da hierarquia escolar, rompendo as barreiras da seleção universitária e dos cursos considerados de "excelência", ou seja, aqueles mais disputados, em que há comumente uma predominância de estudantes oriundos das classes abastadas. Como

\footnotetext{
${ }^{1}$ Fonte: Revista Ensino Superior - Apesar das falhas, Fies e Prouni melhoram o acesso ao ensino superior. Ed. 231, ano 2018. Disponível em: http://www.revistaensinosuperior.com.br/fies-e-prouni-expandiram-matriculas/ Acesso em: 17/03/19.
}

Barbarói, Santa Cruz do Sul, Edição Especial n.54, p.<94-111>, jul./dez. 2019 
esse grupo de indivíduos tem sido objeto contínuo de estudo e da análise sociológica da educação, interessa cruzar as diferentes abordagens que o olham em sua complexidade.

\subsection{Estudos precursores: $o$ investimento familiar}

No Brasil, o debate sobre esse tema tem início com os estudos e análises da desigualdade a partir de dados quanti-qualitativos levantados por Nogueira $(1991,1993)$ sobre as trajetórias escolares e as estratégias culturais utilizadas pelas classes populares para chegar ao ensino superior. Para a autora, as famílias dos entrevistados foram tocadas pelo processo de escolarização desde muito cedo, tendo-o aprendido como um valor estruturante, "embora este [o estudante] se encontre à mercê da situação econômica e das possibilidades vividas no momento" (op cit., p.94). Trata-se de famílias que entendem investimento escolar como um esforço necessário para que seus filhos acessem o ensino superior e, por conseguinte, tenham condições de garantir um bom trabalho. Dessa forma, o investimento das classes populares na educação dos filhos é a possibilidade de mobilidade e de êxito socioeconômico que a escola oferece aos filhos como contrapartida ao investimento dos pais.

Viana $(1998,2005)$ aprofunda esse tema tendo, como interlocutores, os teóricos franceses contemporâneos, notadamente os escritos de Lahire (1997), inovando na forma como são elaboradas as interpretação do sucesso/fracasso escolar em meios populares. Para isso, apresenta os pontos que considera necessários à investigação das dinâmicas e disposições apresentadas pelas famílias em sua relação com a escola e a formação dos filhos. Sua abordagem das relações entre as diferentes esferas sociais - a família, o filho/aluno e a escola - procura estabelecer tipologias para os casos de sucesso escolar. Por trás das famílias analisadas, funciona um "conjunto de práticas e atitudes voltadas intencionalmente para o rendimento escolar dos filhos" (1998, p. 67). Essas práticas escolares são interpretadas como sinal da mobilização e do empenho imediato dos recursos familiares ou como um "investimento escolar familiar" de longo prazo. Assim, "as oportunidades de chances" constituem o elemento variável que, juntamente com a biografia de cada estudante (o seu retrato) ou individualidade (subjetividade), podem explicar como os jovens se orientam em relação aos cursos e aos objetivos familiares. Sua conclusão é de que o sucesso escolar, tal como se apresenta em seus exemplos, tem relação direta com as práticas do investimento familiar, mas dependem também do indivíduo e de sua vontade para torná-las reais.

Esses trabalhos introduzem o debate sobre as questões de acesso, tendo em vista que os "casos improváveis de sucesso escolar" são provenientes de trajetórias escolares complexas e dinâmicas que tendem a fugir às regras probabilísticas. Assim, se o sucesso escolar é, em Barbarói, Santa Cruz do Sul, Edição Especial n.54, p.<94-111>, jul./dez. 2019 
grande medida, condicionado pela origem social dos estudantes e pelo volume de capitais manipulados pela família de origem, há, no entanto, e apesar disso, estudantes que se desviam desses condicionantes, e isso estaria relacionado à postura de investimento escolar por parte da família e às disposições do indivíduo.

\subsection{Mães, estratégias familiares e situações "espetaculares" de ascensão escolar}

Os estudos realizados por Portes (1993) sobre as trajetórias e estratégias de estudantes universitários das camadas populares colocam em evidência as variáveis responsáveis pelo sucesso de estudantes pobres na universidade pública. O objetivo é compreender as trajetórias e as estratégias empreendidas pelas famílias de baixa renda para viabilizar um nível de escolaridade não comum a esse meio social. Para Portes, as famílias entrevistadas apresentam um projeto escolar pensado a longo prazo, o qual denominou ser a "força do ethos", que consiste no investimento familiar materializado na figura da mãe e apoiado no valor simbólico da escola como possibilidade de ultrapassar a condição de precarização e de vulnerabilidade social do grupo de origem.

Em sua tese sobre a trajetória e a vida acadêmica de estudantes pobres em cursos de grande concorrência da Universidade Federal de Minas Gerais (UFMG), Portes (2001) discute a luta desses estudantes para ingressarem e se manterem nos cursos mais concorridos da carreira universitária, como Medicina, Direito, Computação, Engenharia Elétrica e Fisioterapia. Apoiado em dados históricos e registros orais, aborda a experiência vivida por esses estudantes em um contexto elitizado do ensino superior, ou seja, de trajetórias que o autor denomina "trajetórias estatisticamente improváveis" (PORTES, 2001, p. 49). Seu interesse em investigar essas situações "espetaculares" está relacionado com as bases teóricas da sociologia da educação e que se ocupam dos casos "paradigmáticos", em que a origem social indica a probabilidade dessas situações ocorrerem com mais facilidade nos meios populares. O autor mostra como esses estudantes aparecem na literatura sociológica, destacando alguns pontos importantes: i. o estudante de "sucesso" é apontado como brilhante, vencedor das adversidades, ii. aquele que galga postos valorizados e desejados. Por outro lado, o sucesso alcançado reforça a discriminação sobre os estudantes que "fracassam" e não conseguem atingir as notas de corte exigidas pelos cursos mais concorridos. Os estudantes que alcançam o sucesso escolar vencem barreiras territoriais (geográficas, econômicas, culturais) que os põem num outro patamar se comparados aos demais estudantes pobres.

O trabalho de Silva (1999), por sua vez, mapeia, registra e interpreta as estratégias implementadas por jovens residentes no Complexo da Maré/RJ para entrar na universidade Barbarói, Santa Cruz do Sul, Edição Especial n.54, p.<94-111>, jul./dez. 2019 
pública. Essa pesquisa enfoca os jovens que, apesar de compartilharem um mesmo ambiente físico, uma localidade, um território, constroem estratégias diferentes dos demais a partir das suas trajetórias de sucesso escolar. O objetivo de Silva nesse trabalho é "compreender as variáveis que se fazem presentes na permanência do aluno na escola" (op cit., p. 107), seja ela de curta ou longa duração. Para isso, busca identificar os elementos centrais das trajetórias dos estudantes da Maré - um local de característica proletária e de grande diversidade cultural - que devem ser interpretados, segundo o autor, em função de sua "plurifatoriedade", ou seja, tanto pelos aspectos que realçam o lado objetivo quanto por aqueles que enfatizam o lado subjetivo dos indivíduos, assim como pela interpretação dos contextos secundários que a eles estão ligados.

De posse do registro de relatos e falas, o autor reconstrói onze trajetórias escolares bem-sucedidas para depois conectá-las ao envolvimento da família e dos parentes. Dois tipos de família são destacadas: a "educógena" (op cit., p. 118) e a "de investimento diversificado" (op cit., p. 121). A primeira vê a escola como um instrumento de ascensão social, sendo a mãe aquela que faz de seu esforço um produto do conjunto familiar. Para esse tipo de família, a universidade pública parece ser o principal objeto de desejo, principalmente devido à gratuidade e ao status que adquire aquele que ingressa na instituição. Já as famílias que se interessam por outros meios de aquisição, e que não possuem valores escolares, isto é, não apresentam um projeto de escolaridade, acabam percebendo a escola como uma "obrigação social". Nesses casos, são os primogênitos que assumem as responsabilidades dentro do espaço doméstico ou no trabalho, sendo sacrificados pela organização da casa em função da manutenção dos irmãos mais jovens. Essas famílias, diferentemente das famílias educógenas, são inclinadas a se distanciarem do ensino, desviando-se da educação dos filhos e gerando pouco investimento escolar, pois acreditam que a ascensão social de seus membros pode acontecer por outras vias, como, por exemplo, através do casamento. Trata-se de um modelo de família ausente, que atribui o sucesso escolar dos filhos à escola, eximindo-se dessa responsabilidade. Os pais entendem que é a "inteligência institucional" e o esforço dos filhos para assimilar os conhecimentos veiculados na escola que permitem com que o núcleo familiar obtenha êxito (op cit., p. 126), bem como é à escola que cabe desenvolver nas crianças os valores e o gosto pelo estudo.

O trabalho de Zago (2000a, 2006), que aborda a relação da escola com a família, procura enfatizar o forte apelo social que essa temática suscita no âmbito das políticas públicas, bem como das transformações ocorridas na educação e no perfil dos estudantes de sucesso, particularmente em relação aos processos de escolarização em meio popular. A Barbarói, Santa Cruz do Sul, Edição Especial n.54, p.<94-111>, jul./dez. 2019 
autora demonstra que a relação família (mãe) e escola sofre processos periódicos de reconfiguração e mudanças de significados. Sua análise dos percursos escolares no ensino fundamental e médio nos meios populares aponta que, para esses estudantes, a instituição escolar é vista como uma referência para entrar no mercado de trabalho. Seu estudo demonstra que o ensino médio é decisivo para aqueles que almejam qualificação profissional e trabalhos bem remunerados, o que normalmente vem acompanhado pela ambição universitária. Para essa autora, porém, a presença das camadas populares no ensino superior não oculta as diferenças sociais que separam os estudantes pobres e ricos, que tenta manter intocável a imagem da instituição escolar como um ambiente plural, por isso a importância de se conhecer as demandas e as práticas escolares desses atores, suas sutilezas e tramas.

Considerando que as questões do fracasso e do sucesso escolar, no Brasil, servem para debater as desigualdades de oportunidades e a probabilidade desse fenômeno ocorrer em famílias de baixa renda e de fraco capital cultural, a partir dos anos 2000 observamos um deslocamento do olhar sociológico a respeito dos estudantes de origem popular na universidade, como uma renovação dos estudos voltados ao sucesso/fracasso escolar e que apontam para outros contextos, tipos diferentes de estudantes, bem como para diferentes abordagens metodológicas.

\subsection{Políticas públicas e subjetividade nos casos de sucesso escolar em meios populares}

A tese de Honorato (2005), que enfoca a ascensão social de estudantes de origem popular na universidade pública, diferentemente dos outros estudos aqui apresentados, se opõe aos paradigmas dominantes do campo da sociologia da educação ao sugerir que o percurso desses estudantes não é determinado somente pelo investimento, práticas e estratégias geradas no interior das configurações familiares e/ou do ambiente de convivência. Em sua interpretação, os filhos das classes populares são mais suscetíveis a conjunturas socioeconômicas e políticas e, portanto, mais dependentes do investimento público e da assistência escolar.

Para essa autora, que também se utiliza das autobiografias e narrativas dos estudantes, seriam os elementos estruturais e o incentivo público que os influenciam no momento de optar pelo ensino superior e escolher a carreira universitária, sendo o investimento familiar pouco determinante para a classe popular. Esses estudantes seriam, portanto, mais suscetíveis às conjunturas políticas, às práticas democráticas da sociedade civil, às políticas públicas de investimento escolar, aos blocos de status, elementos que tornam seus diplomas mais 
valorizados socialmente ${ }^{2}$. A mobilidade social dos estudantes não se explicaria somente pela ação do grupo familiar, mas pela determinação dos estudantes - influenciados pelos status que os diplomas adquirem na sociedade - em superar as barreiras do ensino médio e ascender ao ensino superior. Por outro lado, a autora sustenta que a universidade pública é reprodutora dos valores e dos créditos de herança, contribuindo para uma constante (re)classificação social dos indivíduos, sem de fato alterar suas vidas. Os estudantes pesquisados foram os primeiros de suas famílias a chegarem à universidade, de modo que apresentam uma grande conformidade à escola e às regras escolares; no entanto, omitem outros condicionantes que contribuíram para sua trajetória escolar do ensino fundamental/médio à universidade pública. Sua conclusão é de que, os estudantes de origem popular, para concretizarem o sonho escolar/profissional, dependem menos dos recursos herdados dos pais e mais do desenvolvimento econômico nacional, das práticas e da compreensão da sociedade, bem como da conjuntura política e da dinâmica das políticas públicas de assistência educacional.

O estudo de Piotto (2007), realizado na área de psicologia social sobre estudantes das camadas populares na universidade pública, mostra um olhar diferente, mas igualmente revelador das disparidades sociais existentes no campo da educação brasileira. Ao buscar conhecer a trajetória escolar e a experiência universitária de estudantes de cursos superiores de alta seletividade oriundos das camadas populares de São Paulo, ajuda aprofundar e a conhecer os sentidos atribuídos pelos estudantes para seu ingresso e permanência no ensino superior público. Procura discutir, assim, o que significa - da perspectiva do estudante construir uma trajetória de sucesso e, a partir de seu discurso, retratar as subjetividades que agem nesse processo, realçando o fato de que experiências individuais acumuladas durante sua trajetória escolar são definidoras para a entrada nos cursos de excelência. As narrativas desses estudantes demonstram a dualidade que caracterizam essas trajetórias de sucesso, de um lado, marcada por lutas, esforços e humilhações, e que a autora chama de desenraizamento, de outro lado, é responsável pela transformação das suas perspectivas de vida escolar, social e de inserção econômica. Porém, se a entrada na universidade é menos traumática porque ocorre em "pé de igualdade", durante a fase da formação, as diferenças culturais e a falta de determinados capitais envolvidos se torna um peso na medida em que esses estudantes avançam no ambiente acadêmico. Para a autora, esses estudantes entendem que a atividade de "estudar" é uma atividade laboral e não uma atividade de prazer ou de obrigação. Essa compreensão por parte dos estudantes de origem popular acerca de suas

\footnotetext{
${ }^{2}$ Os blocos de status implicam uma transferência dos conflitos do lugar simbólico da democracia para o campo da justiça (HONORATO, 2005, p.126).
}

Barbarói, Santa Cruz do Sul, Edição Especial n.54, p.<94-111>, jul./dez. 2019 
trajetórias está em consonância com o pensamento daqueles que seguem o que ela denomina de "uma pedagogia do trabalho" (op cit., p.299) como forma de vencer as dificuldades que lhes são impostas.

A tese de Piotto expressa a influência da determinação psicológica e da autodisciplina, no campo da Sociologia da Educação, como fatores que devem ser investigados, uma vez que essas informações permitem fazer um contraponto entre os elementos internos e externos que constituem esse objeto de estudo. Como a pesquisa anterior, entretanto, Piotto considera que os recursos públicos e as políticas educacionais, assim como o modo como os indivíduos operacionalizam os contextos de sua trajetória escolar, são essenciais para a permanência e o êxito do estudante de origem popular na universidade pública.

\subsection{Os efeitos da expansão do ensino superior nas trajetórias de estudantes de baixa renda}

O trabalho de Santos (2009) a respeito do acesso e da permanência de estudantes de origem popular do curso de Saúde na Universidade do Recôncavo Baiano é bastante ilustrativo e atual, pois aborda uma área científica onde a entrada do estudante de origem popular é tida como muito pouco provável: a Medicina. A autora realizou sua pesquisa em uma região predominantemente negra, tendo como pressuposto o fato de esses estudantes sofrerem discriminações por conta de sua origem racial e da localização geográfica onde vivem. Seu estudo abarca os estudantes negros nascidos nas regiões com pouco investimento social ou distantes dos grandes centros urbanos, elementos geográficos determinantes para a exclusão de muitos jovens da periferia e que confirmam a forma desigual como certos grupos sociais são tratados no Brasil. O interesse em estudar esse fenômeno está no fato de que essa situação de desigualdade racial começou a mudar em função das políticas afirmativas (cotas, bolsas, financiamentos, etc.) que deram ao estudante de origem popular negro as condições para poder se desenvolver academicamente. Como os cursos de Medicina são muito elitizados, o acesso a essa formação é apenas uma parte dos desafios que o estudante negro da periferia tem de enfrentar, sobretudo aquele que não possui tradição universitária na família. Por outro lado, o valor simbólico de passar em um curso com as características da Medicina eleva o status do indivíduo dentro da comunidade, fazendo com que seja visto como referência para os demais jovens.

A autora (SANTOS, 2017) argumenta que essa situação ocorre porque é difícil para o estudante negro se impor como um igual no contexto pesquisado, tendo em vista que os cursos de Medicina são espaços de contraste - cursos de brancos - e de grande competição Barbarói, Santa Cruz do Sul, Edição Especial n.54, p.<94-111>, jul./dez. 2019 
por notas e menções honrosas. No entanto, para os estudantes que ingressaram no contexto das políticas e cotas de ações afirmativas, essa realidade não é um entrave e parece poder ser superada paulatinamente, na medida em que, através da iniciativa do Estado, veem suas chances de equidade aumentarem. Sua conclusão é de que a permanência desses estudantes em cursos como a Medicina, bem como a superação da situação de excepcionalidade dependem, essencialmente, de uma distribuição equitativa das oportunidades educacionais, o que passa, por sua vez, por iniciativas que dão a eles o suporte necessário para que consigam concluir sua formação, tais como: bolsas, restaurantes universitários, residência estudantil, entre outros benefícios (SANTOS, 2017, p. 48).

Silva Souza (2009), por sua vez, acompanhou a presença dos estudantes da escola pública de origem popular em diferentes cursos de graduação de uma universidade federal no sul do país (UFRGS), destacando suas características socioeconômicas e os diferentes caminhos trilhados por esses estudantes no ambiente universitário, suas assimetrias e contrastes, aprofundando as variáveis que contribuem para sua chegada na universidade federal. A partir da análise dos cursos e das características socioeconômicas dos estudantes e de 17 entrevistas com estudantes de diferentes cursos, tendo por base as suas "narrativas de vida", de forma individualizada, apresenta histórias compartilhadas pelos estudantes durante a observação de campo.

Para esse autor, o êxito do estudante de origem popular na universidade federal não é consequência do mérito pessoal, como muitos alunos sugerem, nem da qualidade das escolas como poderiam supor os educadores. O êxito desse estudante depende, portanto, da forma como são motivados, de como aprendem a manipular os saberes e na maneira como organizam a partir de uma situação de vulnerabilidade trajetórias escolares de sucesso. Seu trabalho é inovador porque destaca o peso que a instituição universitária exerce na vida dos estudantes de origem popular, na medida em que é vista ao mesmo tempo como um lugar de desejo e disputa(s), mas que se torna um lugar de diversidade e de organização social. Desse modo, é necessário pensar a universidade como uma "região teórica", um terreno, um lugar de conflitos e de transições onde o estudante assume diferentes formas e tipos, com possibilidades infinitas de encaixes, socializações e disposições (SILVA SOUZA, 2016).

Finalmente, o estudo de Nierotka e Trevisol (2016) trata diretamente do papel e da importância das políticas nas trajetórias de estudantes de origem popular na universidade pública. Os autores entendem que as políticas de ampliação de acesso à educação superior são decisivas para a transformação da sociedade, sobretudo porque beneficiam os meios populares. Visando conhecer melhor os indicadores que estimulam essas mudanças, Barbarói, Santa Cruz do Sul, Edição Especial n.54, p.<94-111>, jul./dez. 2019 
realizaram um estudo sobre os estudantes das camadas populares matriculados em uma universidade pública criada mais recentemente (Universidade da Fronteira Sul, UFFS). Esse estudo é exemplar da tendência atual que busca explicar a trajetória de sucesso e de fracasso desses novos atores e profissionais com base na expansão e desenvolvimento da estrutura educacional e da ação das políticas assistenciais de educação colocadas à disposição das classes populares.

No caso da UFFS, entendem que os reflexos da ação governamental e da política das cotas raciais/sociais mudou positivamente a realidade institucional, mas não suficientemente. A partir dessa política, houve uma rápida transformação da estrutura universitária vista na mudança do perfil do estudante que ingressa na instituição, ou seja, houve ampliação de acesso. Trata-se de estudantes trabalhadores, com origem em famílias de renda baixa, situados entre a classe D e E, que necessitam, porém, de financiamento público para poder dar continuidade aos estudos superiores, sem o qual não há "sucesso". O insucesso escolar aparece, no entanto, como um problema recorrente entre os estudantes de origem popular matriculados na UFFS, segundo o autores, em razão da falta de uma pedagogia universitária que tenha acompanhado a transformação do perfil do estudante. $O$ fato de suas especificidades não serem levadas em conta dentro da instituição faz com que esses estudantes se mostrem inseguros em relação ao curso escolhido e a seu futuro profissional.

Como vemos, a abordagem dos autores da sociologia da educação nacional que pesquisam os estudantes de origem popular na universidade revela a variedade de explicações e a complexidade da questão acerca do sucesso (ou do fracasso) escolar, para a qual a resposta é sempre multifatorial. O conjunto de informações fornecido pelos autores da sociologia das desigualdades e da educação superior compõe, assim, um mapa ou enciclopédia acerca dos mananciais de socialização e das práticas culturais com as quais os estudantes de origem popular se deparam na família, na escola e na universidade, que os formam e os transformam ao longo da vida estudantil, e dos quais emerge toda a sua diversidade e complexidade em termos de disposições, posturas e culturas. Buscando aprofundar as características desses sujeitos, bem como sua própria percepção de sucesso escolar - questão normalmente tratada objetivamente, mas que, na prática, é vivida subjetivamente, como deixam entrever alguns dos trabalhos - realizamos uma pesquisa que segue a esteira dos estudos qualitativos aqui apresentados.

\section{O sucesso escolar visto da perspectiva de estudantes da escola pública}

\subsection{Desenho e objetivos da pesquisa}


Nossa pesquisa ${ }^{3}$ analisou a trajetória de estudantes oriundos do ensino fundamental e médio público do Rio Grande do Sul (RS) matriculados nos cursos mais concorridos de uma universidade federal (Universidade Federal do Rio Grande do Sul, UFRGS), situada na capital, e de uma universidade comunitária (Universidade de Santa Cruz, UNISC), situada no interior do estado. Foram considerados, nesse caso, somente aqueles estudantes que vieram da escola pública e que conseguiram ser aprovados em cursos considerados de prestígio social e/ou científico, ou seja, cursos bastante disputados e almejados pela maioria dos estudantes que prestam o vestibular, o que os coloca, socialmente, em uma situação de sucesso no contexto do ensino médio público. São estudantes de cursos que tiveram as maiores demandas do concurso vestibular na região (2017-2018), entre eles: Medicina, Arquitetura, Engenharia da Computação, Engenharia Mecânica, Direito, Biomedicina, Enfermagem, Administração e Psicologia.

Assim, para explicar seu sucesso escolar - aquele de quem vê de fora, antes de tudo -, buscamos, como a maioria dos autores citados, compreender os contextos familiares, sua caminhada até a universidade, mas nos diferenciamos ao destacar as suas percepções do sucesso escolar - visto de dentro - a partir de sua experiência escolar (em retrospectiva) e universitária (in loco), ou seja, de sua transição para o ensino superior. O trabalho de campo nos aproximou do dia-a-dia desses estudantes e da maneira como, retrospectivamente, narram e explicam seu percurso estudantil até o presente momento, em que se encontram em etapa inicial ou intermediária da formação universitária.

O material qualitativo derivado do encontro com esses jovens universitários permite: i. discutir a desigualdade das oportunidades educacionais no sistema da educação superior pública e privada, ii. traçar o perfil socioeducacional dos estudantes e de seus familiares, iii. descrever as trajetórias escolares desses estudantes, do ensino fundamental à vida universitária, sendo esses dois últimos pontos alcançados com base na análise de quadros ou retratos que foram abstraídos de suas narrativas e vivências pessoais, com base em uma microssociologia. O corpus de estudo é composto pelos dados obtidos por meio de um roteiro, com indicadores sociais e econômicos das famílias, e pelas entrevistas em que os participantes explanam suas trajetórias e justificam seu sucesso escolar ${ }^{4}$. Trata-se, assim, de um trabalho qualitativo, eminentemente analítico, na medida em que aborda as relações estabelecidas pelos estudantes através do valor ou da qualidade que atribuem às experiências vividas, vistas

\footnotetext{
${ }^{3}$ Para mais detalhes, ver Aguiar Neto (2019).

${ }^{4}$ As informações foram transcritas e lidas com a ajuda do Programa NVivo11 (2017), o que nos permitiu fazer uma leitura mais geral por temáticas, mas também acompanhar, individualmente, como se situavam em relação aos tópicos propostos (cf. AGUIAR NETO, 2019)
}

Barbarói, Santa Cruz do Sul, Edição Especial n.54, p.<94-111>, jul./dez. 2019 
principalmente em comentários apreciativos, bem como na recorrência de determinados assuntos, que constituem padrões ou ideias emergentes, e que respondem às questões apresentadas a eles durante a abordagem.

\subsection{Da escola pública a cursos universitários de prestígio: quem são esses estudantes?}

Nossos entrevistados são estudantes moradores, em sua maioria, de bairros periféricos, vilas ou pequenas cidades do interior do estado, e que se encontram nas cercanias da rede metropolitana de Porto Alegre (RS). Um universo escolar de sucesso composto predominantemente por mulheres, confirmando a tendência da mulher em assumir sua emancipação em relação à família (boa parte das entrevistadas mora fora de casa), bem como sua busca por uma posição escolar mais qualificada (diferentemente do(a)s pais/mães). Observou-se também que a maior parte dos entrevistados é beneficiária de algum tipo de programa de assistência educacional, seja para o ensino público, com as bolsas e cotas raciais, seja para o ensino privado, com o financiamento do Prouni ou do Fies. ${ }^{5}$

Mesmo sendo "filhos" da escola pública, esses jovens apresentam situações financeiras (renda pessoal e/ou familiar) diferenciadas entre si. Os estudantes inscritos na instituição federal comprovam ser de baixa renda e dependentes de $\operatorname{Cotas}^{6}$. Os pais desses estudantes não ultrapassam o ensino médio completo, vivendo de trabalhos manuais e renda média; as mães possuem ensino médio completo e algumas delas atingem o nível superior, mas trabalham em empregos de baixa remuneração. Não seria exagero classificar, no cômputo geral, que a maior parte desses estudantes apresenta renda baixa ou se encontra em uma situação de classe média pobre - no limite do que poderíamos considerar classe média -, pois não se sustenta sozinha ou vive uma vida materialmente precária junto aos grupos de origem, com muitas limitações. A situação dos estudantes que se encontram no ensino universitário

\footnotetext{
${ }^{5}$ Quanto às bolsas de iniciação científica (IC) ou de monitoria, modalidade complementar a outros benefícios, vale salientar que na universidade comunitária, o número de estudantes com bolsa de IC segue um programa próprio compatível com o da UFRGS, o PUIC (Programa Universitário de Iniciação Científica), além de ser contemplada, assim como a instituição federal, com bolsas da FAPERGS e do CNPQ.

${ }^{6}$ De acordo com os dados da Pesquisa do Perfil Socioeconômico dos Estudantes das Universidades Federais, divulgada em 2018 pela ANDIFES (Associação Nacional dos Dirigentes das Instituições Federais de Ensino Superior) - que corresponde ao período de expansão recente ocorrido entre os anos de 2000 a 2016 -, a maioria dos estudantes das universidades federais, no Brasil, advém de famílias com renda per capita de até um salário mínimo e meio. Esses jovens são na sua maioria estudantes pardos e negros, que cursaram todo o ensino médio em escola pública e com pais que, diferentemente deles, não tiveram acesso ao ensino superior. Nas universidades federais, os estudantes pretos e pardos constituem a maioria dos estudantes, quando somados, tornaram-se maioria absoluta (51,2\% do total). No entanto, mesmo demonstrando um equilíbrio escolar essa porcentagem está abaixo da média da população brasileira, em que essa categoria social atinge $60,6 \%$ do total da população nacional, ocupando os piores empregos e as atividades menos remuneradas.
} 
privado também é variável, pois, mesmo que essas famílias vivam uma situação econômica um pouco mais confortável se comparada aos estudantes da universidade pública, os custos com o estudante torna-se um fardo. As mensalidades e/ou taxas do financiamento estudantil (Fies/Prouni) não deixam de ser pagas com a ajuda de estratégias familiares, através de sacrifícios de outros aspectos de sua vida social, ônus com o qual os estudantes das federais não precisam arcar.

Observa-se, assim, que os casos de sucesso escolar que identificamos não estão restritos a uma classe extremamente pauperizada, ou seja, àqueles que se encontram na parte mais pobre da sociedade e que, quando na universidade, poderiam ser considerados realmente casos improváveis de sucesso escolar por terem na renda um fator determinante de sua vulnerabilidade. Do mesmo modo, percebe-se que a maneira como a organização das famílias (seus encaixes) dá origem a "estilos de sucesso" independe do volume de capital social, cultural e econômico, confirmando que os estilos moldados pela atitude positiva dos pais em relação à escola e pela relação dos estudantes, quando em idade escolar, com os professores criam estímulos desde cedo para a vida estudantil e fazem emergir a crença em sua capacidade de estudar e assimilar conhecimento.

Não por acaso, os entrevistados, de modo geral, tendem a reproduzir o discurso do mérito pessoal, supervalorizado na sociedade, na escola e nas próprias famílias e que é identificado pelos pesquisadores do terreno (SILVA SOUZA, 2009, por exemplo). A escolha do curso universitário é outro traço comum a esses estudantes: diferentemente de outros, esses jovens não estão inscritos nos cursos em que lhes foi possível entrar, mas nos cursos que escolheram estar, demonstrando apreço a eles e confiança no que o diploma poderá lhes proporcionar em termos de condições de trabalho e ascensão social. Assim, dentro deste novo ambiente socializador, é também à ideia de mérito, traduzida em suas palavras por esforço, dedicação, estudo, entre outras, que tendem a se apegar. É, na verdade, o que têm de mais concreto no momento presente: se seu esforço (bem como de sua família) deu certo até aqui, deverá continuar dando certo no percurso universitário e mesmo depois, no mercado de trabalho.

No entanto, o fato de o ensino superior ter alargado sua mobilidade, ampliando as possibilidades de acesso, não alterou a conjuntura desigual na educação de base nem tampouco as condições socioeconômicas das famílias, que dependem de uma estrutura material para formar seus filhos, mesmo em instituições públicas. Isso é logo percebido pelos estudantes da universidade federal oriundos do meio popular, para quem as dificuldades enfrentadas dentro da universidade - devidas a defasagens de saberes disciplinares, Barbarói, Santa Cruz do Sul, Edição Especial n.54, p.<94-111>, jul./dez. 2019 
linguísticas (sobretudo em línguas estrangeiras), materiais etc. - passam a ser atribuídas às falhas do sistema escolar e à política educacional, isto é, passam a ser estruturais, e não mais relativas ao mérito pessoal ou familiar. Nesse ambiente, predomina um sentimento de desvantagem social e econômica que os coloca numa situação de inferioridade se comparados aos demais alunos do curso.

Assim, o que liga nossos entrevistados ao conjunto dos estudantes do meio popular é que eles advêm de grupos familiares que conseguem se adaptar e fornecer aos filhos os estímulos e o aporte emocional, financeiro e escolar necessários para poderem chegar e se manterem, mesmo que com dificuldades, na universidade, fatores determinantes tanto para o sucesso escolar como para sua ascensão profissional. O volume de capital desses estudantes de renda baixa não apenas ratifica a conduta adotada nos tempos da escola pública (onde prevalecia seu intelecto e autonomia), como demonstra que as disposições sociais e culturais que lhes são características advém de famílias que valorizam a educação, a cultura letrada, o que aumenta a capacidade desses "casos improváveis" de se adaptarem ao ambiente universitário e perseverarem, como já havia sido debatido por Lahire (1997). Por isso, a escolaridade dos pais/familiares e/ou o apreço que demonstram pelo conhecimento tem o poder de alterar o jogo e os limites da mobilidade estudantil, aumentando as chances e o êxito dos estudantes, na medida em que a ação e o comportamento social da família que valoriza o saber reforça, na formação escolar dos filhos, o gosto pela busca do conhecimento e do saberfazer. É inegável, todavia, em nosso contexto, o papel das políticas de educação e assistência estudantil promovidas pelo Estado, mesmo não sendo lembradas muitas vezes nos relatos coletados. Essas políticas, tanto quanto todos os outros aspectos discutidos acima, abriram caminho para que esses estudantes chegassem à universidade (cotas e financiamentos), criando brechas para que esses jovens fossem incluídos no sistema de formação e profissionalização educacional.

\section{3 Últimas considerações: por que a trajetória de sucesso escolar em meio popular deve ser considerada um terreno sensível?}

Os estudos aqui comentados, pela complexidade de seu objeto, mas também por afetarem a configuração de nossa sociedade, exigem um olhar sensível por parte do pesquisador, uma capacidade de interagir com o terreno e de não fragilizar ou superestimar esses indivíduos e seus contextos, que são dinâmicos. Tendo em vista que as diferenças geralmente associadas a esses estudantes correspondem a variáveis socioeconômicas e culturais que se convertem em desigualdade de acesso - tais como a renda, a escolaridade dos 
pais, os tipos de escola frequentada, o bairro, a cor, entre outros elementos -, as metodologias qualitativas voltadas para esse tipo de terreno têm o papel de fornecer uma tradução mais aprofundada do tema e suscitar posturas engajadas. Dentre essas metodologias, chamamos a atenção para uma abordagem que tem sido pouco discutida em âmbito nacional, conhecida como terrenos sensíveis.

O termo terrenos sensíveis (BOUILLON et al., 2006; VULBEAU, 1998, 2007; AGUIAR NETO, 2009; HENNEQUIN, 2012; BRITO, PESCE, 2015), tomado emprestado da Geografia pela Antropologia e outras disciplinas das Ciências Humanas, e ainda pouco difundido no Brasil, abarca temáticas associadas a grupos humanos, instâncias ou lugares de vulnerabilidade, exclusão, precariedade e sofrimento, ou seja, situações que ferem ou constituem ataques aos direitos civis e humanos. Também se considera sensível a abordagem desses terrenos, no sentido de que seu estudo implica sensibilidade por parte do pesquisador que é afetado pelo objeto, transformando-o em uma causa que demanda uma postura de engajamento. Como explica Vulbeau (1998), existem duas correntes possíveis e básicas de significação que ajudam a elucidar o problema dos temas e dos terrenos sensíveis: i. uma primeira linha associada às sensações e à capacidade emocional que se refere ao significado pessoal daquele que é sensível e que reage às coisas sensíveis e, ii. uma segunda linha que pode ser identificada e associada às questões sensíveis, justamente por possuir "volume" ou características que lhes dá densidade suficiente para serem percebidas e consideradas importantes socialmente. A noção do sensível e da sensibilidade ajudam, dessa maneira, a combinar o terreno a um território concreto onde a vida cotidiana é evidenciada, mas que, por conta das suas ambivalências, produz indivíduos frágeis e vulneráveis.

A partir da revisão bibliográfica dos estudos nacionais que abordam o estudante de origem popular no ensino superior, vários são os elementos que nos permitem considerar tal temática no âmbito dos terrenos sensíveis: i. o investimento escolar constitui um esforço necessário, coletivo, para o acesso ao ensino superior; ii. as trajetórias desses estudantes possuem sentido, são definidoras do lugar do indivíduo no território e de suas disposições; iii. o fato de, ao obterem êxito, serem associados a situações espetaculares, em razão das barreiras geográficas, culturais e econômicas que superam; iv. o fato de se formarem em um ensino médio público, precário se comparado ao ensino médio privado, sendo que esta etapa é determinante para o acesso ao ensino superior e a longevidade escolar; v. o fato de que o êxito se torna uma obrigação para esses jovens, em que a atividade estudantil é equiparada à atividade laboral; vi. o fato de que seu ingresso ao ensino superior altera seu status no interior de seu grupo de origem, transformando a relação com seus pares; vii. quando implicada uma 
característica étnica relativa a uma minoria socioeconômica e cultural (negro, indígena, imigrante etc.), soma-se aos outros elementos a discriminação por tipo físico e cultural; viii. o fato de a universidade ser um lugar de conflitos e transições, onde o estudante deve aderir a diferentes princípios e regras; ix. o fato de a própria instituição universitária não estar preparada para acolher esse perfil de estudante, com uma pedagogia que leve em conta suas especificidades; x. o fato de esse estudante, e a camada da população por ele representada, necessitar de políticas assistenciais de longo prazo, que intervêm em todos os demais elementos.

\title{
SCHOOL SUCCESS PATHWAYS AMONG STUDENTS OF PUBLIC SCHOOL IN THE UNIVERSITY: A SENSITIVE PROBLEM?
}

\begin{abstract}
This paper outlines the main contributions of national research that describe and problematize successful school and / or university trajectories of young people from popular backgrounds in Brazil, between 1990 and 2018. Commonly treated within the Sociology of Education, this theme is revisited here from different approaches and perspectives, which complement each other, forming a panel of the situation, which culminates in the latest expansion of the higher education system through the implementation of public policies and assistance programs (lived between 2000 and 2016). This last period is devoted to a study that specifically covers the transition of young people from public high school to prestigious university formations, considering their characteristics, but also their perceptions of school success. In addition, due to the specificities of the analyzed population, the particularities of the field research undertaken, as well as the fact that this theme directly affects the equality of chances and, consequently, the Brazilian social mobility, we propose that it be treated as a sensitive theme by the Humanities and Social Sciences, approach discussed at the end of the text.
\end{abstract}

Keywords: School success; students of popular origin; Sensitive land.

REFERÊNCIAS

AGUIAR NETO, J.M. Da escola pública à universidade: trajetórias de sucesso escolar. Tese de Doutorado - Programa de Pós-Graduação em Ciências Sociais, PUCRS, 2019.

Maison de L'Amitié: L'expérience d'un réseau social à La Défense auprès de SDF. Master 2 CIT's - Departament des Sciences de L'Education, Paris Ouest Nanterre, 2009.

BRITO, O.; PESCE, S. De la recherche qualitative à la recherche sensible. Rev. Especificités, $n^{\circ} 8$, Nanterre Paris X, 2015.

BOUILLON, F. FRESIA, M. TALLIO, V. (orgs.) Terrains Sensibles: expériences actuelles de l'anthropologie, Centre d'étudies africaines, EHESS, Paris, 2006

HENNEQUIN, E. (org.) La Recherche á l'épreuve des terrains sensible : approches en Sciences Sociales, Ed. L'Harmattan, Paris, 2012. 
HONORATO, G. Estratégias coletivas em torno da formação universitária: status, igualdade e mobilidade entre desfavorecidos. Dissertação (Mestrado em Sociologia). Rio de Janeiro: PPGSA/IFCS/UFRJ, 2005.

LAHIRE, B. Sucesso escolar nos meios populares: as razões do improvável. Tradutores: Ramon Américo Vasques e Sônia Goldefer, São Paulo, Ed. Ática, 1997.

NIEROTKA, R.L.; TREVISOL, J.V. Os jovens das camadas populares na universidade pública: acesso e permanência, Revista KATAL, Florianópolis (SC), v. 19, nº1, (22-32p.), jan/2016.

NOGUEIRA, M.A. Trajetórias escolares, estratégias culturais e classes sociais - notas em vista de construção do objeto de pesquisa. Revista Teoria e Educação, n. 03, (89-112p.), 1991.

Trajetórias escolares e estratégias familiares de estudantes universitários provenientes de classes médias. Projeto de Pesquisa, FAE-UFMG/CNPq, 1993.

PIOTTO, D.C. As Exceções e suas Regras: estudantes de camadas populares em uma universidade pública, Instituto de Psicologia, Dissertação de Doutorado Psicologia Universidade de São Paulo (USP), São Paulo (SP), 2007.

PORTES, E.A. Trajetórias e estratégias escolares do universitário das camadas populares. Dissertação (Mestrado em Educação) - Departamento de Pós-Graduação de Educação, Universidade Federal de Minas Gerais (UFMG), Belo Horizonte, 1993.

Trajetórias escolares e vida acadêmica do estudante pobre da UFMG: um estudo a partir de cinco casos. Tese (Doutorado em Educação) - Faculdade de Educação da Universidade Federal de Minas Gerais (UFMG), Belo Horizonte, 2001.

SANTOS, D.B.R. Para além das Cotas: a permanência de estudantes negros no ensino superior como política de ação afirmativa. Tese de Doutorado (Departamento de Educação) - Universidade Federal da Bahia - UFB, Salvador (BA), 2009.

Curso de branco: uma abordagem sobre o acesso e a permanência de estudantes de origem popular nos cursos de Saúde da Universidade Federal do Recôncavo da Bahia UFRB, Revista Contemporânea de Educação, v.12, n ${ }^{\circ}$ 23, (31-50p.), 2017.

SILVA, J.S.E. "Por que uns e não outros?" Caminhada de estudantes da Maré para a universidade. Tese de Doutorado (Departamento de Educação da PUC), Rio de Janeiro (RJ), Ed. Pontifícia Universidade Católica (PUCRJ), Tese de Doutorado, 1999.

SILVA SOUZA, J.V. Alunos de escola pública na Universidade Federal do Rio Grande do Sul: portas abertas. Tese de Doutorado Programa de Pós-Graduação em Educação, UFRGS, 2009.

VIANA, M.J.B. Longevidade escolar em famílias de camadas populares: algumas condições de possibilidades, Tese de Doutorado (Faculdade de Educação), Universidade Federal de Minas Gerais (UFMG), Belo Horizonte, Ed. UFMG, 1998. 
. As práticas socializadoras familiares como locus de contribuição de disposições facilitadoras de longevidade escolar em meios populares, In: Revista Educação e Sociedade - UNICAMP, Campinas (SP), v. 26, n. 90, (107-125p.), 2005.

VULBEAU, A. Em terrain de connaissances. In: Hommes et Femmes de terrain, Revue Informations sociales, n. 72, Université de Nanterre, Paris, 1998.

. L'approche sensible des quartiers "sensibles" - une posture de proximité, Revue

Informations Sociales - Familles et quartiers sensibles, n. 141, juillet, 2007.

ZAGO, N. Quando os dados contrariam as previsões estatísticas: os casos de êxito escolar nas camadas socialmente desfavorecidas, Revista Paidéia - FFCLRP - USP, Ribeirão Preto (SP), (70-80 p.), 2000a.

Do acesso à permanência no ensino superior: percursos de estudantes universitários de camadas populares. Revista Brasileira de Educação, v.11, n.32, (226- 237p.), 2006.

\section{Sobre o autor:}

Jorge Morgan de Aguiar Neto possui Doutorado em Ciências Sociais (PUCRS), Mestrado em Ciências da Educação (Université de Paris Ouest Nanterre), Mestrado em Sociologia (UFRGS, 2002) e Graduação em Ciências Sociais com habilitação em Antropologia (UNB). Sua atuação docente e científica se concentra nas seguintes áreas: sociologia da educação, sociologia do trabalho, sociologia e antropologia aplicada à saúde, antropologia cultural e política. Endereço Eletrônico: jmorganrs@ hotmail.com 